\title{
Contraplacental Hypogastrinemic Effect of Gastrin Infusion in Sheep
}

\author{
FRANK H. MORRISS, ${ }^{(28)}$ JR., SHARON S. CRANDELL, PAUL A. PALMA, AND \\ LENARD M. LICHTENBERGER \\ Houston Perinatal Nutrition Laboratory, Departments of Pediatrics and Physiology, The University of Texas \\ Health Science Center at Houston, Houston, Texas, USA
}

\begin{abstract}
Summary
Infusion of gastrin, $\mathrm{G}-17 \mathrm{I}$, at $0.4 \mu \mathrm{g} / \mathrm{min}$ into either the maternal or fetal venous circulation of six late gestation sheep was associated with increases in serum gastrin concentration in the infused circulation and reciprocal decreases in the serum gastrin concentration in the other circulation (contraplacental) that perfused the placenta. Pentagastrin infusion at $0.4 \mu \mathrm{g} / \mathrm{min}$ was associated with an increase in C-terminal specific gastrin immunoreactivity in both the infused and the contraplacental circulations. These observations suggest that biologically active fragments of gastrin, but not the intact molecule, may cross the ovine placenta. An alternative explanation for our results is that gastrin infusion into either the maternal or fetal circulation which perfuses the placenta may result in the release of an inhibitor (i.e., somatostatin) into the other circulation. Of broad importance, these observations indicate that although intact polypeptide hormones may not traverse the placenta, their concentrations in maternal and fetal sera may not be as independent as previously believed. Serum gastrin half-life values in late gestation sheep fetuses, lambs, and ewes were determined to be $13.7 \pm 1.9,16.7$ \pm 2.6 , and $15.2 \pm 2.8 \mathrm{~min}$, respectively. These similar values indicate that the relatively high serum gastrin concentrations observed in near-term sheep fetuses are not the result of prolonged half-life in the fetus.
\end{abstract}

Gastrin promotes growth of the gastrointestinal tract after birth $(11,15)$. Its role in the development of the fetal gastrointestinal tract, however, has not been clearly defined, nor has the regulation of fetal circulating gastrin concentration been elucidated. Gastrin appears in fetal gastrointestinal tissues and serum late in gestation, and its concentration in the serum increases rapidly, so that at birth there is hypergastrinemia relative to adults in several species $(2,4,8,12,14,17,18,21,22,26)$. In sheep, for example, fetal serum gastrin is first detected at about $117 \mathrm{~d}$ gestation. It increases linearly thereafter, surpassing the mean maternal serum gastrin concentration $(20.0 \pm 1.5 \mathrm{fmol} / \mathrm{ml})$ after $124 \mathrm{~d}$ gestation (14). By the end of gestation at $145-147 \mathrm{~d}$, fetal serum gastrin concentration is approximately 3 times the maternal concentration. The lack of correlation between maternal and fetal serum concentrations of gastrin, the absence of an umbilical venoarterial concentration difference, and the demonstration of gastrin present in gastrointestinal tissue concomitant with its appearance in serum in the fetus support the hypothesis that circulating gastrin in the fetus arises from fetal tissues rather than by transplacental passage. Furthermore, as a general observation in most species, polypeptide hormones do not traverse the placenta.

On the other hand, there is some evidence that maternal events influence fetal gastrin physiology. Infusion of gastrin into preg- nant dogs 1 wk before term significantly stimulates fetal gastric secretion (5), an observation that suggests the transplacental passage of gastrin or of a smaller, but biologically active fragment such as pentagastrin. Somewhat conversely, we recently found evidence in rats that physiologic concentrations of endogenous maternal gastrin in some undefined manner retard the development of fetal tissue gastrin concentration (13). Reduced maternal serum gastrin levels produced experimentally by either surgical or dietary manipulation were associated with elevated fetal antral and duodenal gastrin concentrations. This observation suggests that under normal conditions there may be transplacental inhibition of fetal gastrin synthesis.

The present investigations were performed to determine if gastrin, G-171, and/or its smaller, but biologically active fragment, pentagastrin or G5, traverse(s) the ovine placenta directly, and to seek further evidence of maternal suppression of fetal gastrin synthesis and release.

\section{MATERIALS AND METHODS}

Preparation of sheep. Six typical western range ewes, primarily a Dorset-Rambouillet mixed breed, were bred for these investigations and maintained on an open range until several days before surgery, which was performed between 116-136 d gestation. Under $5 \mathrm{mg} / \mathrm{kg}$ pentobarital sodium sedation and spinal anesthesia with $6 \mathrm{mg}$ tetracaine hydrochloride (Pontocaine $\mathrm{Hy}-$ drochloride) and hyperbaric glucose, each ewe was operated to implant polyvinyl catheters in the fetal iliac artery and vein and maternal femoral artery and vein. In selected animals the common umbilical vein was also catheterized $(14,19)$.

After recovery from surgery, the ewes were kept in stainless steel pens and allowed sweet feed (Omolene, Ralston Purina, St. Louis, MO) and water ad libitum. Catheters were flushed daily with heparin. Procaine penicillin G (600,000 U) and streptomycin $(0.5 \mathrm{~g})$ were administered for three postoperative d. Beginning on the 4th postoperative d, each animal was studied. Four protocols were employed in these investigations.

Protocols 1 and 2. transplacental transfer of gastrin (G-17I). To investigate the possibility of maternal-to-fetal transfer of gastrin across the placenta, gastrin (G-17I, Research Plus, Bayonne, $\mathrm{NJ}$ ) was infused into the maternal venous catheter, and blood samples obtained from the maternal and fetal arteries were analyzed for gastrin concentration. To investigate the fetal-tomaternal transfer of gastrin, gastrin was infused into the fetal peripheral venous circulation, and blood samples obtained from the maternal and fetal arteries were analysed for gastrin concentration. In each of these two protocols, normal saline was infused for $30 \mathrm{~min}$ before the gastrin was infused for the subsequent 60 $105 \mathrm{~min}$. Blood samples were obtained at 15 -min intervals during the saline infusion and continuing throughout the gastrin infu- 
sion for a total of three pre-gastrin infusion baseline samples and four to seven samples taken during gastrin infusion. The rate of saline or gastrin infusion was $0.2 \mathrm{ml} / \mathrm{min}$. The concentration of gastrin in the infused solution was adjusted to provide a rate of gastrin infusion of $0.4 \mu \mathrm{g} / \mathrm{min}$ into either the maternal circulation (four experiments in three ewes) or fetal circulation (eight experiments in six ewes).

Protocol 3: transplacental transfer of pentagastrin (G5). To investigate the possible transplacental transfer of this small molecule, pentagastrin (Ayerst Laboratories, NY) was infused at 0.4$1.6 \mu \mathrm{g} / \mathrm{min}$ into the maternal circulation of two ewes; the following day pentagastrin was infused at $0.4 \mu \mathrm{g} / \mathrm{min}$ into the fetal circulation. Blood samples were collected as in the above experiments; however, these blood samples were assayed for pentagastrin + gastrin using a C-terminal specific antibody as described below.

Protocol 4: half-life of gastrin in fetal and maternal circulations. On five occasions in four animals into which gastrin was infused via the fetal circulation at $0.4 \mu \mathrm{g} / \mathrm{min}$ for $60 \mathrm{~min}$, at least five serial fetal arterial blood samples for gastrin assay were obtained at timed intervals throughout the $75 \mathrm{~min}$ immediately after the infusion was terminated. In addition, the half-life of gastrin in the circulation of one ewe was obtained on three occasions after the infusion of gastrin at $2 \mu \mathrm{g} / \mathrm{min}$ for $60 \mathrm{~min}$; one study was performed during late pregnancy and two were performed during the first postpartum week. The $t_{1 / 2}$ was calculated from the slope (k) of the linear regression of ln gastrin concentration as a function of time according to the relationship $t_{1 / 2}=0.693 / \mathrm{k}$.

Gastrin radioimmunoassay. Serum gastrin levels were determined by radioimmunoassay by the technique of Yalow and Berson (27) as modified by Walsh (23). Antibody No. 1296, kindly donated by Dr. Morton I. Grossman (Center for Ulcer Research and Education) was used to assay serum gastrin concentration in the gastrin infusion studies (6). This antibody reacts with all of the established circulating forms of gastrin (G-17I, G34 ), but it has a low affinity for pentagastrin. Purified human gastrin G-17I, kindly donated by Dr. Morton I. Grossman (Center for Ulcer Research and Education), was used as both standard and label. Gastrin was iodinated by the chloramine-T technique and was later purified by the method of Stadil and Rehfeld (20).

Pentagastrin radioimmunoassay. An estimate of the gastrin + pentagastrin concentration in the sera was obtained by radioimmunoassay using an antisera which recognizes the C-terminal tetrapeptide of the molecule. Raised in rabbits in our laboratory, this antisera (Ab. No. 4) recognizes both pentagastrin and gastrin equipotently. It was used in the radioimmunoassay at a final titer of 1:50,000 (16).

\section{RESULTS}

Maternal gastrin infusion. Gastrin infused into the ewe at 0.4 $\mu \mathrm{g} / \mathrm{min}$ was associated with a rapid increase in maternal arterial serum gastrin concentration that was sustained throughout the period of infusion and quickly returned to baseline levels after the infusion ceased. By $60 \mathrm{~min}$ after the initiation of the infusion, maternal serum gastrin values had increased $180-865 \%$ from the pre-infusion baseline concentrations that averaged $44.0 \pm 12(x$ $\pm \mathrm{SEM}) \mathrm{fmol} / \mathrm{ml}$. As shown in Figure 1, fetal serum gastrin concentrations decreased to values that were $56-77.5 \%$ of the respective pre-infusion fetal baseline concentration $(42 \pm 4.5$ $\mathrm{fmol} / \mathrm{ml})$. Both the increase in maternal $(P<0.025)$ and decrease in fetal $(P<0.01)$ concentrations were significant by paired $t$ tests.

Fetal gastrin infusion. The results of fetal gastrin infusion studies are shown in Figure 2. Serum gastrin increased in each fetus by 60 min to values that were $350-4000 \%$ the respective pre-infusion baseline concentrations for which the mean value was $22.1 \pm 3.7 \mathrm{fmol} / \mathrm{ml}$. Maternal serum gastrin concentration in seven of the eight experiments declined to $44-91.5 \%$ of the respective pre-infusion baseline values for which the mean value

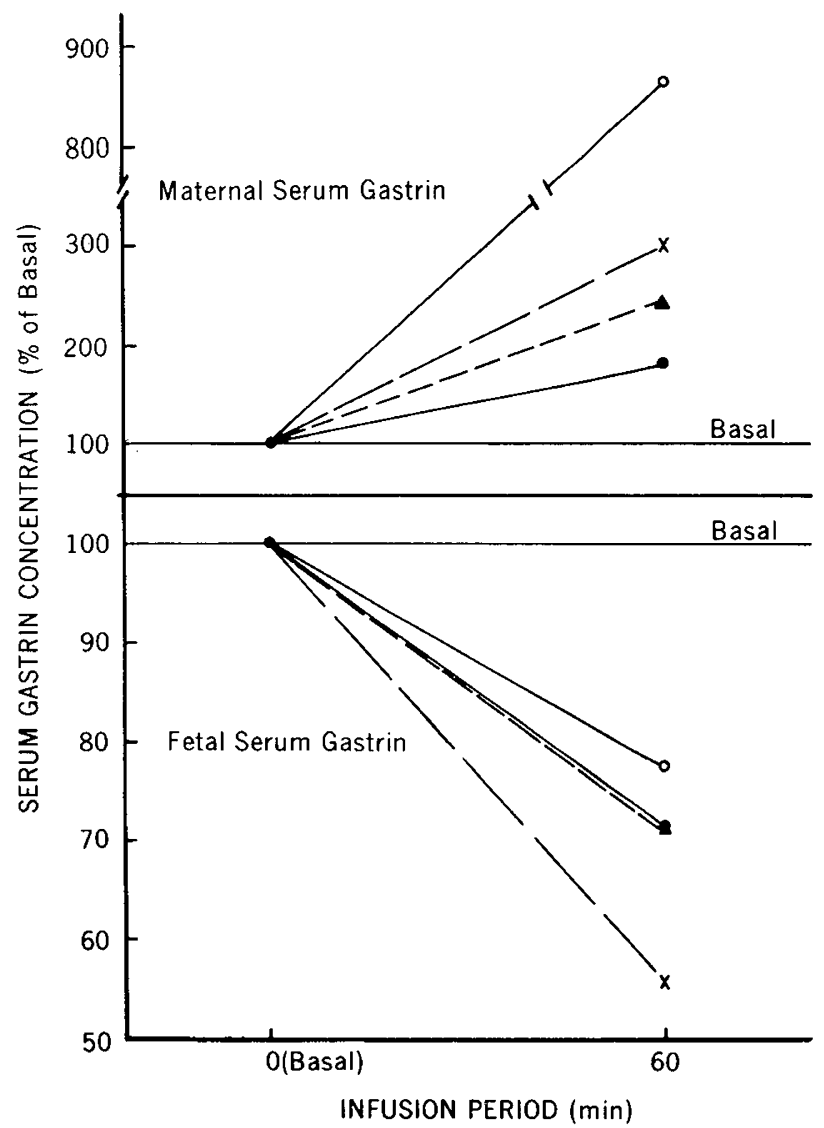

Fig. 1. Effect of maternal venous infusion of gastrin, G-17I, at 0.4 $\mu \mathrm{g} / \mathrm{min}$ for $60 \mathrm{~min}$ on maternal (top) and fetal (bottom) arterial serum concentrations of gastrin in late gestation sheep.

was $43.0 \pm 7.5 \mathrm{fmol} / \mathrm{ml}$. Both the increase in fetal $(P<0.01)$ and decrease in maternal $(P<0.05)$ concentrations were significant by paired $t$ tests.

Transplacental pentagastrin transfer. In each of five trials, infusion of pentagastrin into either the ewe or the fetus was associated with increases in gastrin immunoreactivity in the contraplacental circulation as measured with the C-terminal specific antibody. The results in Figure 3 demonstrate that infusion of pentagastrin into the maternal circulation was associated with an increase in fetal serum hormone concentration after a delay of $30 \mathrm{~min}$. A similar relationship was observed after infusion of pentagastrin into the fetus. Infusion of pentagastrin into the ewe was associated with increases in fetal serum gastrin of 81,156 , and $178 \%$ from baseline; infusions into the fetus were associated with increases in maternal serum gastrin of 100 and $195 \%$.

Half-life of gastrin. In three fetuses the $t_{1 / 2}$ for gastrin calculated from the rate of disappearance of gastrin immunoreactivity from the fetal circulation after cessation of exogenous gastrin infusion was $13.7 \pm 1.9 \mathrm{~min}$. The disappearance curve for one fetus is shown in Figure 4 . The $t_{1 / 2}$ for gastrin in the lamb in the first week after birth was $16.7 \pm 2.6$ and the $t_{1 / 2}$ for gastrin in the ewe was $15.15 \pm 2.8 \mathrm{~min}$.

\section{DISCUSSION}

In the experiments described above we have presented evidence that administration of exogenous gastrin (G-17I) into the maternal or fetal vessels, which results in a many-fold increase in the serum gastrin concentration in the infused circulation, is not accompanied by elevations in hormone level in the noninfused circulation that perfuses the placenta. From these observations we infer that G-17I does not cross the ovine placenta 


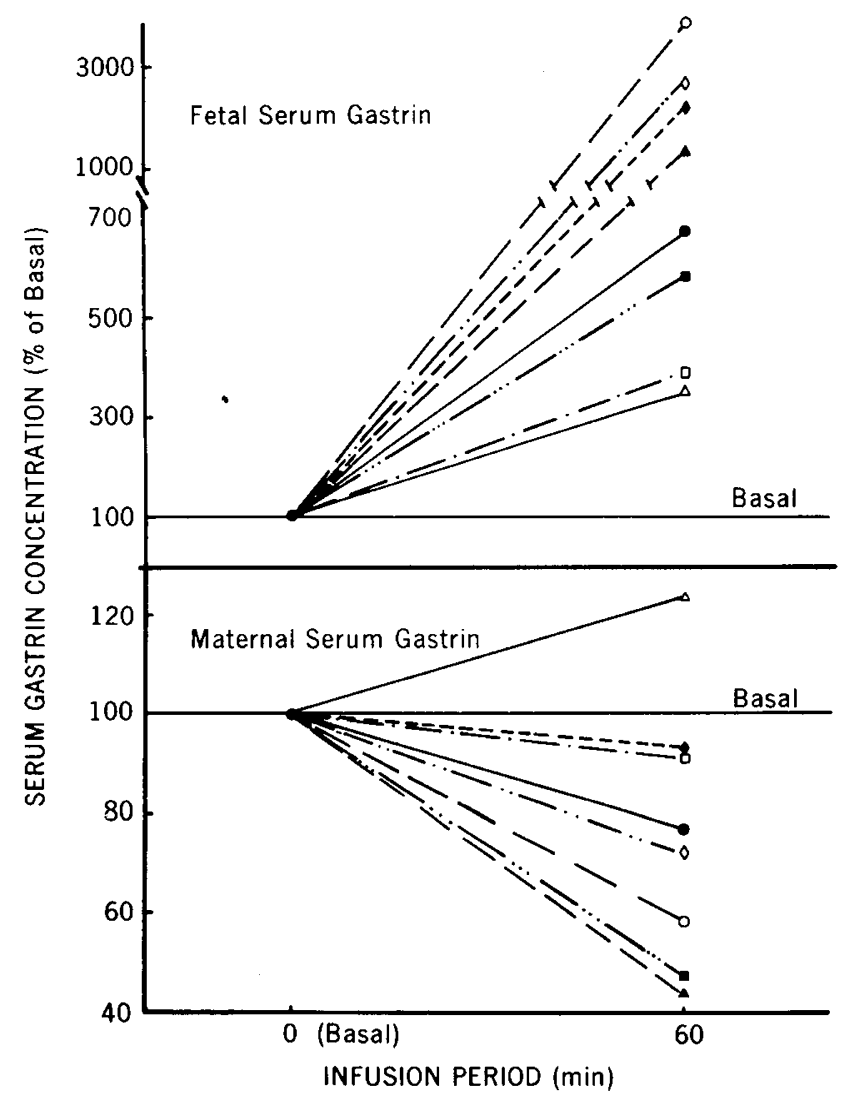

Fig. 2. Effect of fetal venous infusion of gastrin, G-17I, at $0.4 \mu \mathrm{g} / \mathrm{min}$ for $60 \mathrm{~min}$ on fetal (top) and maternal (bottom) arterial serum gastrin concentrations in late gestation sheep.

intact. In fact, infusion of G-17I into the circulation of either ewe or fetus is associated with a significant decrease in serum gastrin concentration in the circulation that perfuses the opposite aspect of the trophoblast. These findings suggest that although intact gastrin does not traverse the ovine placenta, fetal and maternal serum gastrin levels may be reciprocally influenced by each other in perturbation experiments. Whether the reciprocal influence observed under these conditions occurs in the unperturbed pregnancy is unclear.

The mechanism for the contraplacental decrease in serum gastrin concentration may be attributable to the passage across the placenta of a smaller, but biologically active fragment of gastrin. Under the constructs of this hypothesis the gastrin present, for example, in the maternal circulation would be metabolized to a biologically active fragment which would then traverse the placenta to enter the fetal circulation. The increase in blood concentration of a C-terminal gastrin fragment would not be detected reliably by our gastrin radioaminoassay because the antibody employed (No. 1296) has much greater affinity for the intact gastrin molecule than it does for C-terminal fragments of the hormone (6). On the other hand, elevations in the concentration of a biologically active gastrin fragment may result in a decrease in the endogenous hormone concentration in serum for at least two reasons. First, it is well documented that exogenous administration of pentagastrin and other C-terminal gastrin derivatives results in a brisk stimulation of gastric acid secretion and a subsequent decrease in the $\mathrm{pH}$ of gastric juice in mature animals (24). This increase in gastric acidity, in turn, results in the abolition of gastrin release by the activation of a $\mathrm{pH}$-sensitive inhibitory mechanism (24). But this negative feedback loop, which is operative in the ewe, may not be operative in the fetal lamb. Second, it has been reported that pentagastrin administration stimulates the release of somatostatin, a potent inhibitor of

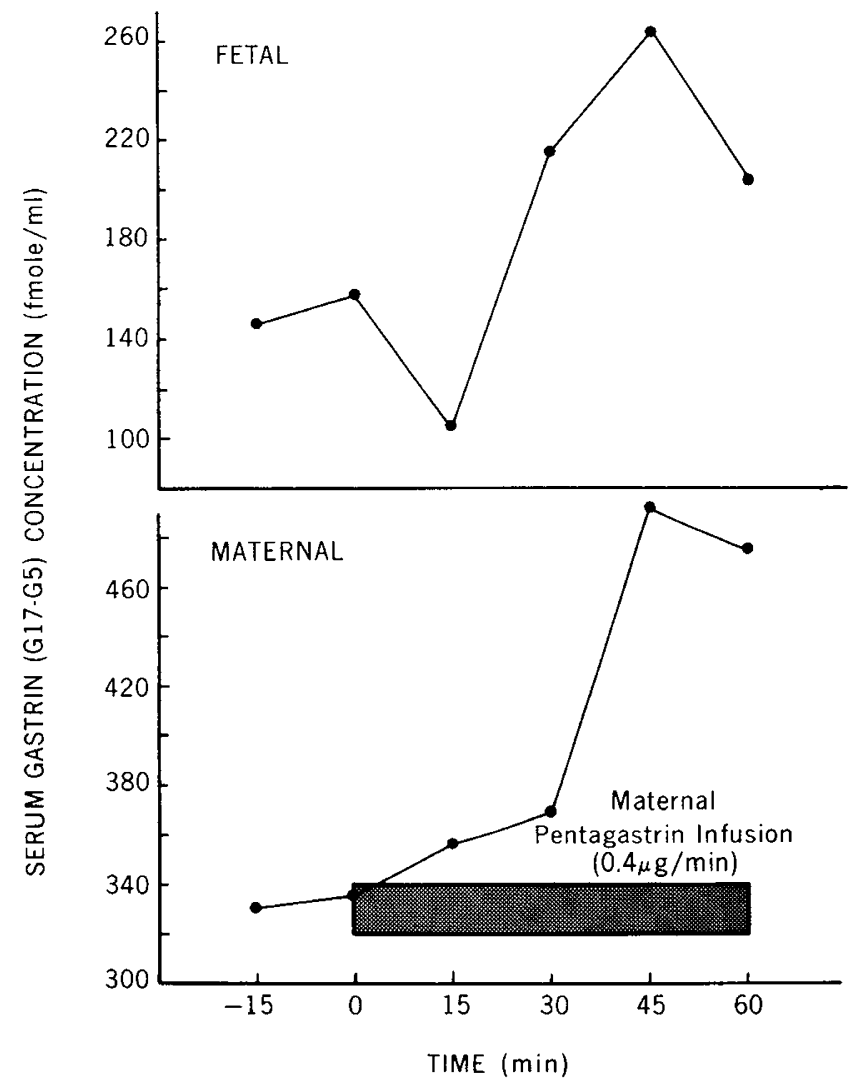

Fig. 3. Effect of maternal venous infusion of $0.4 \mu \mathrm{g} / \mathrm{min}$ pentagastrin, $\mathrm{G} 5$, for $60 \mathrm{~min}$ on fetal (top) and maternal (bottom) arterial serum concentrations of G-17I + G5 in a late gestation sheep.

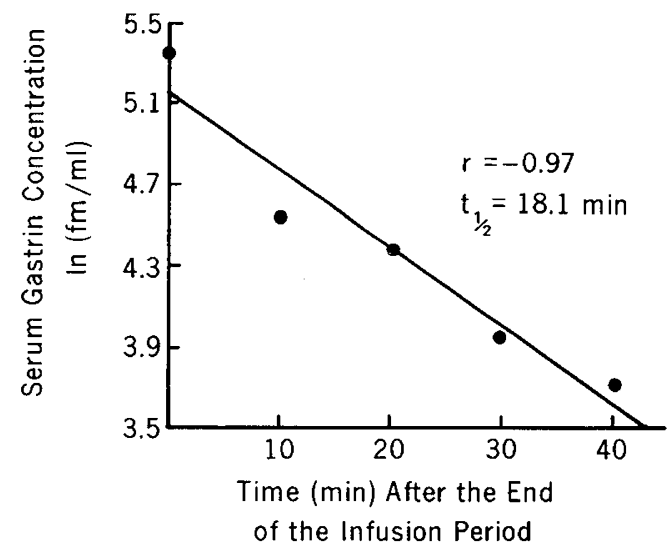

Fig. 4. Disappearance of gastrin, G-17I, from the fetal arterial circulation following a 60 -min infusion of gastrin, G-17I, into the fetal venous circulation in a late gestation sheep. Shown on the ordinate is the ln fetal serum gastrin concentration.

gastrin release from a variety of tissues $(3,10)$. Somatostatin, an inhibitory peptide originally isolated from the hypothalamus, is known now to be present in D-cells in many other organs, including the stomach and the placenta $(1,26)$. It is thus conceivable that elevations in the serum concentration of a biologically active fragment of gastrin may inhibit endogenous gastrin release secondarily by inducing the release of somatostatin from one of these tissues.

Using a radioimmunoassay that detects pentagastrin as well as gastrin, we have demonstrated parallel increases in both maternal and fetal circulations when pentagastrin is infused into either 
circulation; thus, we have demonstrated that biologically active fragments of gastrin may cross the placenta. This demonstration appears to explain the mechanism that leads to fetal gastric acid secretion when gastrin is infused into pregnant rats (4). Garzon et al. (9) showed that fetal rat target tissues can respond to pentagastrin in late gestation (9), an observation that lends additional support to the hypothesis that gastrin is broken down to pentagastrin which then traverses the placenta to stimulate gastric acid secretion in the rat. Paradoxically, the suckling rat has been reported to be refractory to gastrin and its analogues due to the absence of specific gastrin receptors during the suckling period (21). From these studies, it appears quite probable that gastrin may be broken down to form a biologically active fragment which traverses the placenta and influences gastrin homeostasis in the contraplacental circulation.

An alternate hypothesis that we have considered to explain the observation of contraplacental reciprocal gastrin concentrations involves the transplacental passage of somatostatin. Because it is a smaller molecule than gastrin (14 instead of 17 amino acid residues in length), somatostatin may be able to traverse the placenta to inhibit gastrin release in the contraplacental circulation. Of special interest in relation to this possible explanation of our results is the recent cytochemical demonstration of immunoreactive somatostatin present in the cytotrophoblast of the immature human placenta (26). It is not clear whether the somatostatin demonstrated in placenta was traversing the placenta, synthesized and released by placenta, or present in the placenta as a target organ. Moreover, whether the fetal G-cell is under the control of somatostatin released by the D-cell or acquired transplacentally in late ovine gestation is not known.

The half-life of gastrin in the fetal sheep circulation late in gestation was $13.7 \pm 1.9 \mathrm{~min}$, a value similar to those in the lamb and ewe, but greater than the half-lives for gastrin in mature subjects of some other species (25). This observation suggests that the previously reported late gestational fetal hypergastrinemia is not likely to be the result of prolonged fetal half-life. There is suggestive evidence that the elevated gastrin levels at birth may be the result of increased release of gastrin (7). One possible explanation for a late fetal and neonatal hypersecretory state which arises from the results of the present study is that the hypersecretion of gastrin is a manifestation of a derepression response as the fetus escapes from influences present in utero. The concentration of the putative inhibitors in the fetal circulation would be dependent on the levels of biologically active gastrin and gastrin fragments in the maternal blood in late gestation. In support of this possibility, we earlier reported evidence that tissue gastrin levels are abnormally elevated in the unborn fetuses of rats that had sustained an experimentally induced gastrin deficiency (13). On the other hand, there is evidence of hyposecretion of acid in several species examined during the period of neonatal hypergastrinemia $(8,17,21,26)$, suggesting that an open negative feedback loop may also contribute to the elevation of serum gastrin levels at birth.

These investigations failed to demonstrate evidence of the transplacental passage of intact gastrin in either direction across the placenta of sheep in late gestation. There is, however, evidence that pentagastrin or another biologically active fragment of gastrin crosses the placenta. Elevations of serum gastrin on one side of the placenta produced by exogenous gastrin infusion into that circulation are associated with decreases in hormone concentration in the contraplacental circulation. There appears, therefore, to be a reciprocal relationship between maternal and fetal gastrin levels in utero. Of broad importance, these observations indicate that although intact polypeptide hormones may not traverse the placenta, their concentrations in maternal and fetal sera may not be as independent as previously believed.

\section{REFERENCES AND NOTES}

1. Alumets, J., Sundler, F., and Hakanson, R.: Distribution, ontogeny and ultrastructure of somatostatin immunoreactive cells in the pancreas and gut. Cell Tis. Res., 185: 465 (1977).

2. Ban, J. L. Reeder, D. D., Clendinnen, B. G., Hirose, F. M. Miller, J. H., and Thompson, J. C.: Concentrations of antral gastrin in the fetal, neonatal and adult dog. Arch. Surg. Chicago, 101: 406 (1970).

3. Barden, N., Cote, J. P., Lavoie, M., and Dupont, A.: Secretion of somatostatin by rat islets of Langerhans and gastric mucosa and a role of pancreatic somatostatin in the regulation of glucagon release. Metabolism 27 (suppl. 1), 9: 1215 (1978).

4. Braaten, J. T., Greider, M. H., McGuigan, J. E., and Mintz, D. H.: Gastrin in the perinatal rat pancreas and gastric antrum: immunofluorescence localization of pancreatic gastrin cells and gastrin secretion in monolayer cell cultures. Endocrinology, 99: 684 (1976).

5. Bruckner W. L. Snow, H. D., and Fonkalsrud, E. W. Gastric secretion in the canine fetus following maternal stimulation: experimental studies on placental transfer of insulin, histamine, and gastrin. Surgery, 67: 360 (1970).

6. Dockray, G. J. and Walsh, J. H.: Amino terminal gastrin in serum of ZollingerEllison syndrome patients. Gastroenterology, 68:222 (1975).

7. Euler, A. R., Ament, M. E., and Walsh, J. H.: Human newborn hypergastrinemia: an investigation of prenatal and perinatal factors and their effects on gastrin. Pediatr. Res., 12:652 (1978).

8. Euler, A. R., Byrne, W. G., Cousins, L. M., Ament, M. E., Leake, R. D. and Walsh, J. H.: Increased serum gastrin concentration and gastric acid hyposecretion in the immediate newborn period. Gastroenterology, 72: 1271 (1977).

9. Garzon, B., Ducroc, R. Onolfo, J. P., Desjeux, J. F, and Geloso, J. P.: Biphasic development of pentagastrin sensitivity in rat stomach. Am. J. Physiol. (Gastrointest. Liver Physiol.), 5: G111 (1982).

10. Ipp, E., Dobbs, R. E., Harriss, V., Arimura, A., Vale, W., and Unger, R. H.: The effects of gastrin, GIP, secretin, and the octapeptide of CCK upon immunoreactive somatostatin release by the perfused canine pancreas. J. Clin. Invest., 60: 1216 (1977)

11. Johnson, L. R., Lichtenberger, L. M., Copeland, E. M., Dudrick, S. J., and Castro, G. A.: Physiologic significance of the tropic action of gastrin. Gastroenterology, 68: 1184 (1975).

12. Larsson, L. I., Hakanson, R., Rehfeld, J, F., Stadil, F., and Sundler, F. Occurrence of neonatal development of gastrin immunoreactivity in the digestive tract of the rat. Cell Tis. Res., 149: 275 (1974).

13. Lichtenberger, L. M.: Dietary induced changes in maternal and fetal gastrin levels and gastrointestinal growth. Fed. Proc., (abstract) 37: 374 (1978).

14. Lichtenberger, L. M., Crandell, S. S., Palma, P. A., and Morriss, F. H.: Ontogeny of tissue and serum gastrin concentrations in fetal and neonatal sheep. Am. J. Physiol., 241: G235 (1981).

15. Lichtenberger, L. M., and Johnson L. R.: A possible role of gastrin in the ontogenic development of the small intestine. Am. J. Physiol., 227: 390 (1974).

16. Lichtenberger, L. M. and Reviczky, A. L.: Affinity chromatography procedure for the purification of gastrin. Gastroenterology, 78: 1207 (1980). (Abstract).

17. Malloy, M. H., Morriss, F. H., Denson, S. E., Weisbrodt, N. W., Lichtenberger, L. M., and Adcock, E. W.: Neonatal gastric motility in dogs: maturation and response to pentagastrin. Am. J. Physiol., 5: E562 (1979).

18. Maxey, P. C. and Trier, J. S.: Endocrine cells in the human fetal small intestine. Cell Tis. Res., 183: 33 (1977)

19. Paxson, C. L., Morriss, F. H., and Adcock, E. W.: Effect of uterine artery insulin infusions on umbilical glucose uptake in sheep. Pediatr. Res., 12: 864 (1978).

20. Stadil, F. R. and Rehfeld, R. F.: Preparation of ${ }^{125}$ I-labelled synthetic gastrin I for radioimmunoanalysis. Scand. J. Clin. Invest. 30:361 (1972).

21. Takeuchi, K., Peitsch, W., and Johnson, L. R.: Mucosal gastrin receptor. V. Development in newborn rat. Am. J. Physiol., 240: G163 (1981)

22. VonBerger, L., Henrichs, I., Raptis, S., Heinze, E., Jonatha, W., Teller, W. M., and Pfeiffer, E. F.: Gastrin concentration in plasma of the neonate at birth and after the first feeding. Pediatrics, 58: 264 (1976).

23. Walsh, J. H.: Radioimmunoassay of gastrin. In: B. Rothfeld: Nuclear Medicine in Vitro. p. 231 (Lippencott, Philadelphia, 1974).

24. Walsh, J. H. and Grossman, M. I.: Gastrin. N. Engl. J. Med., 292: 1324 (1975).

25. Walsh, J. H., Isenberg, J. I., Ansfield, J., and Maxwell, V.: Clearance and acid stimulating action of human big and little gastrins in duodenal ulcer subjects. J. Clin. Invest., 57: 1125 (1976).

26. Watkins, W. B. and Yen, S. S. C.: Somatostatin in cytotrophoblast of the immature human placenta: localization by immunoperoxidase cytochemistry. J. Clin. Endocrinol. Metab., 50:969 (1980).

27. Yalow, R. S. and Berson, S. A.: Radioimmunoassay of gastrin. Gastroenterology, 58: $1(1970)$

28. Requests for reprints should be addressed to: Dr. Frank H. Morriss, Jr., Department of Pediatrics, University of Texas Medical School at Houston, 6431 Fannin, Houston, Texas 77030.

29. This work was supported by National Institutes of Health Grants R01-HD 11337, AM-20686, and P01-HD13021.

30. Received for publication March 1, 1983

31. Accepted for publication September 13, 1983. 